\title{
The Development of Social Enterprise from the point of view of Social Inclusion* $^{*}$
}

\author{
Alan KAY

\begin{abstract}
This paper considers the development of social enterprise in the UK and how this has affected social inclusion. It defines social enterprise and social inclusion and addresses some factors that influence strategy.
\end{abstract}

KEYWORDS: Social inclusion, social exclusion, social enterprise

\section{DEFINING SOCIAL EXCLUSION}

There are a number of definitions for "social exclusion". Arguably, the most enlightened was used by the Social Enterprise Unit within the Department of Trade and Industry (DTI) in 1997 which describes social exclusion as....

“... a shorthand label for what can happen when individuals or areas suffer from a combination of linked problems such as unemployment, poor skills, low incomes, poor housing, high crime environments, bad health and family breakdown..."

This means that social exclusion can be caused by a number of inter-relating factors which include...

- $\quad$ economic factors such as a lack of skills making mainstream employment difficult; low incomes in not very well-paid jobs and thus an inability to advance economically and being caught in a downward poverty cycle; and discrimination in the jobs market and hence becoming more excluded;

- $\quad$ Social factors such as living in a high crime environment which leads to a lack of community cohesion and the resultant suspicion of neighbours; family breakdown causing unsupervised teenagers to roam the streets; a lack of services and opportunities for people and residents to meet and interact; bad health causing people to be less mobile and thus more excluded; and prejudice against a particular group thus causing their social exclusion;

- geographical/structural such as remoteness of the area and far from mainstream services; depopulation of rural areas meaning the population density can no longer maintain the level of services and the area declines and the residents become more excluded; "sink" housing estates with a notorious reputation making it difficult to get a job and move to a "better" area.

It is interesting to note that in England policy-makers talk about "social exclusion" and try measures to counter it while in Scotland practitioners in regeneration tend to refer to "social inclusion" - that is, what can be done to counter the effects of social exclusion.

Alan Kay is an Associate Lecturer at Glasgow Caledonian University, a Member of the Institute for Economic Development, and Director of the Social Audit Network, Community Business Scotland (CBS) Network and the Community Development Journal.

* This article is the original English manuscript translated to Japanese and published as "Eikoku ni Okeru Shakaiteki Kigyou"(Social Enterprise in the U.K.) by the Kobe Institute of Urban Research in "Toshi Seisaku”(Urban Policy), No. 132, pp. 18-34, July 2008. 


\section{DEFINING SOCIAL ENTERPRISE}

There are many definitions for social enterprise. Some definitions are very broad, others more specific. This can cause a great deal of confusion as the general public is still not clear what is a social enterprise and what is not. As more resources are made available for social enterprises, some charitable voluntary organisations call themselves social enterprises. In addition, some private sector companies are also claiming to be social enterprises as they may claim to have socially beneficial impacts.

The DTI UK Government definition is...

"A social enterprise is a business with primarily social objectives whose surpluses are principally reinvested for that purpose in the business or in the community, rather than being driven by the need to maximize profits for shareholders and owners" (Social Enterprise Action Plan: Scaling New Heights)

The Scottish Social Enterprise Coalition definition has a slightly different slant and is...

"Social enterprises are dynamic businesses with a social purpose. They have social aims, trade in competitive markets and reinvest their profits for social and community benefit" (Scottish Social Enterprise Coalition website: $\underline{w w w . s s e c . o r g . u k})$

I was involved in a research programme (CONSCISE Programme - www.conscise.info $)$ a few years ago which defined social enterprise in a more specific, and arguably more helpful way...

"Social enterprises....

.... are not-for-profit,

...seek to meet social aims through trading activities,

...have all assets and wealth held in trust and for the benefit of the community or beneficiaries, and

...encourage participation of members on a co-operative basis with equal rights for all members

- thus accountability to the community or beneficiaries"

Therefore, it is evident that there are a range of different written definitions which can lead to confusion. A few years ago this was a very "hot" topic and a great deal of effort was made in discussing definitions - but it remained largely unresolved. In response to that, the CONSCISE Programme (Pearce, 2003) agreed to define social enterprise and the social economy in a spatial way with the use of a diagram.

In the diagram, the social economy is defined in relationship to other economic systems and the "economy" refers to the provision, production and distribution of goods and/or services. The diagram shows spatially the relationship between three main systems or modes of production. The lines dividing each system are not hard and sharp as there is a transition between sections and their neighbouring sections.

The three economic systems have associated concepts and values. The First System is sometimes referred to as the private sector made up of businesses maximising profit while using resources (labour, environment). First System organisations are based on competition and operate very much in the market economy. The Second System is sometimes referred to the public sector and is based on public service and the managed economy. It is often highly structured and departmentalised. It provides services to society using tax revenue. The Third System is based on organisations with social and/or community aims. It includes a wide range of economic activity from domestic work to social economy organisations. It is not as structured as the other two systems, is loosely defined and fragmented. 


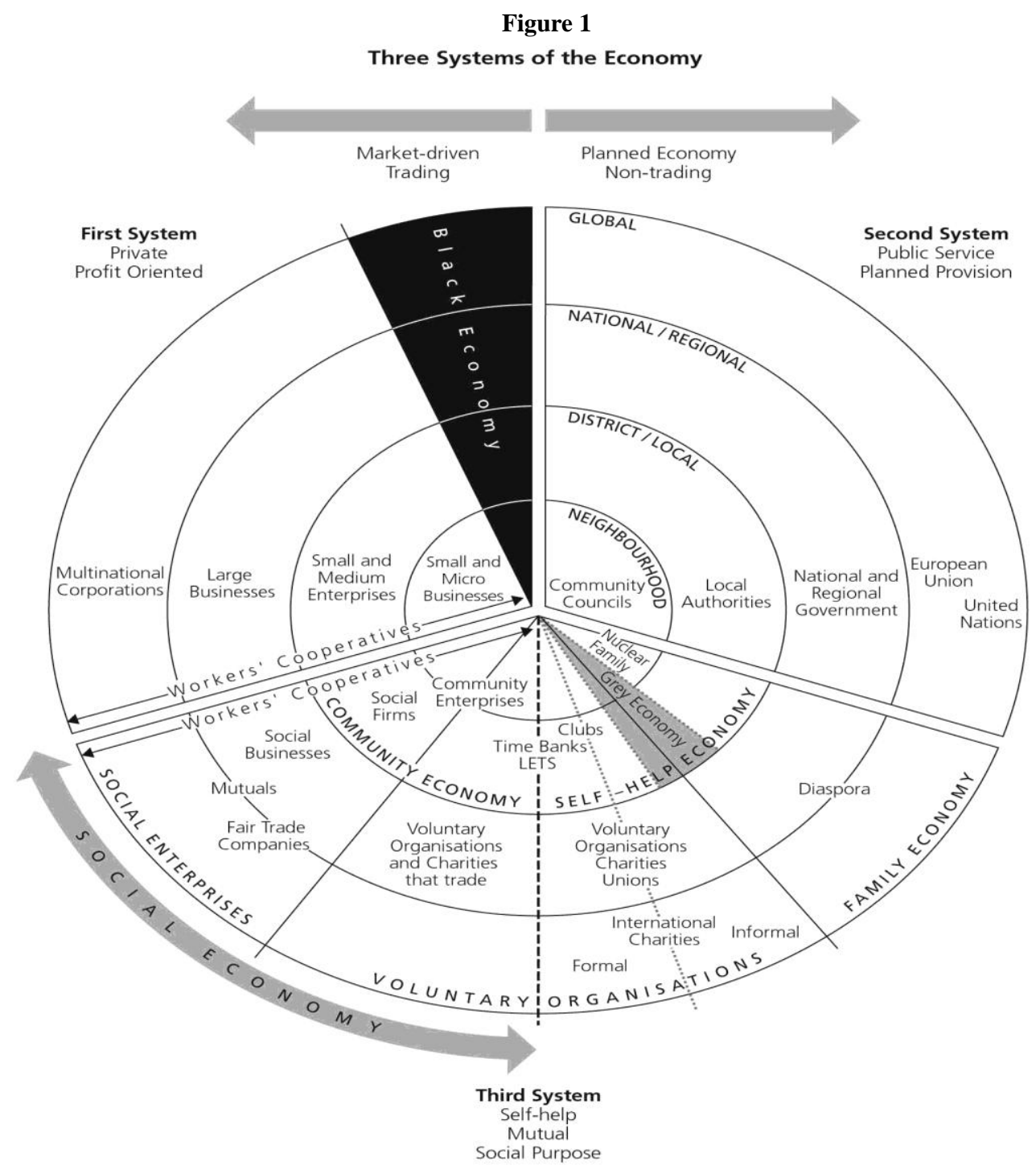

Each system operates at a local, regional and global level as seen by the concentric circles. The whole diagram has been divided into "trading" (left-hand side) and "non-trading" (right-hand side). The illegal economy is in the First System as it is most often involved with individual gain.

On examination of the Third System in more detail, it is made up of social enterprises (which are community enterprises when community-based), voluntary organisations and the family economy. While all social enterprises and community enterprises trade for community or social benefit, some voluntary organisations trade and some do not. Therefore, some are in the social economy and some are not. The social economy is made up of social enterprises and some voluntary organisations depending on their activities.

At the local level (inner circle in the diagram) and in the Third System there are community enterprises, social enterprises affecting a local area, clubs and voluntary organisations in the neighbourhood self-help economy and families. In the Second System there are community councils, community centres, etc.; and in the First System there are small businesses, corner shops, petty criminals, etc. At a local level there are strong links between organisations operating within the each of the three systems. This is where local social capital is located. 


\section{HOW SOCIAL ENTERPRISE CAN BE USED TO TACKLE SOCIAL EXCLUSION}

Social enterprises can be used to tackle social exclusion economically, socially, geographically/structurally and by targeting socially excluded groups. It has to be recognised that these categories are not mutually exclusive. For example, changes in housing stock can influence the local economy, can influence the general health of a population and can impact on the social cohesion of a community.

\subsection{Economically...}

Job creation for the disadvantaged: Social enterprises and often community enterprises attempt to provide work for long term unemployed people. Some social firms who work with disabled people try to provide a "stepping stone" or sheltered employment enabling those employed by a social firm to regain confidence as well as skills making them more able to apply for mainstream employment.

Employment through contracted community services: Often social enterprises are in a good position to not only employ people but also to focus on the provision of a local service. There are social and community enterprises that maintain housing estates, provide landscaping gardening for the open spaces between the housing, provide security services for local employers or owners of the housing stock, or provide employment for homeless people (eg: the Big Issue). Thus social enterprises are able to employ people and provide needed services.

Training programmes: Social enterprises can help the economy by supporting local people and others to become self-employed and start up their own businesses. With the increase in Information Technology more people are able to work from their own homes and self-employment is thus becoming more accessible - but they still need to skills to keep accounts, market their business, etc. Also training programmes can be about "life skills" and helping the most excluded in society to find the confidence to get back into work.

Financial services: Some social enterprises are more specialised and can provide savings and borrowing services. Credit Unions are a specific form of social enterprise and some are becoming very large and influential operating more like banks. Also, some social enterprises are getting into the provision of insurance and travel.

\subsection{Socially...}

Care services locally: Some social enterprises provide care for children or for elderly people. There has been a huge increase in independent After School Clubs that are expected to operate as non-profit-making businesses. There are also children's nurseries that are run as social enterprises. A few homes for the elderly have been started as social enterprises but they are far less common although undoubtedly this is an area that will expand in the future offering opportunities for social enterprises.

Commercial community services: One of the first types of community enterprise were community-owned cafes and shops. They employed people, provided a meeting place and serviced the local community. Also, there are a large number of Workers Welfare Clubs that have always operated as social enterprises although they would not always consider themselves to be "social enterprises".

Using volunteers alongside paid staff and on committees: Many social enterprises, and particularly those that are concerned in care services, have used volunteers. This provides an opportunity for 
volunteering which mobilises volunteers to help others thus helping with community cohesion in a particular area.

\subsection{Geographically and structurally...}

Creating infrastructure - facilitating enterprise: One of the first forms of social enterprise was the community-owned managed workspace. Essentially, this is where the local community takes over a property and converts it into business and office units and rents those out at favourable rates to small and medium sized businesses. The small business tenants then attract people to working in the area and they, in turn, buy things in the local shops and the area is economically stimulated. More recently there has been a huge increase in multi-purpose development trusts which are locally based and operate to benefit the local area by starting businesses, raising funds and working in the general development of the area.

Environmental action: There has been a recent increase in the number of social enterprises that are involved in recycling. Through recycling schemes, social enterprises can employ people, recycle and reuse waste material and reduce the amount of waste that goes into land-fill sites. City farms are another type of social enterprise that introduces city dwellers to country life - it is a form of education and recreation. Also with the interest in energy use, some social enterprises are looking at owning and running wind farms.

Housing services: The independent housing sector has always been strong in the UK and housing co-operatives are not uncommon. These are companies that are owned by the residents who act to improve the houses and surrounding environment. Some of the largest housing associations in the UK are housing co-operatives.

\subsection{Targeting socially excluded groups}

Black/minority/ethnic (BME): A number of social enterprises focus on benefits to a particular group that may in some way be disadvantaged. Refugee support groups have helped refugees set up social enterprises to service the needs of the group.

Women: Some social enterprises work mainly with women - often in training them to start self-employed businesses.

Disabled: There has been a big increase in the number of social firms throughout the UK. Social firms are social enterprises that focus on assisting disabled persons or people recovering from mental illness by employing them in a sheltered environment with a view that they will graduate on to mainstream employment.

Ex-offenders or potential offenders: A number of social enterprises are involved in working with ex-offenders or people that have spent time in prison or a young offender's institute.

Homeless people: One of the most famous social enterprises is the Big Issue that employs homeless people in selling a magazine thus earning them a bit of money. At the same time it uses the magazine to campaign on social issues and gains funds to write and print the articles from advertising.

\section{SOCIAL ENTERPRISE IN THE UK AND SCOTLAND}

The "mapping" of social enterprise is very difficult as definitions are often very wide and, as mentioned before, it is difficult to know what is a social enterprise and what is not. Despite this there is general recognition that the number of social enterprises operating in the UK are expanding. The UK 
government wrote a Social Enterprise Action Plan called "Scaling New Heights" in 2006 and it states:

"In early 2006 the Government extended a mainstream business survey to include social enterprises

....it estimated that at least 55,000 businesses with employees fitted the Government's definition of social enterprise (enterprise derived from data from Small Business Service 2005 Annual Small Business Survey, London: Department of Trade and Industry, combined with large company data from IFF Research (2005) A survey of Social Enterprise Across the UK, London, Small Business Service)...

...This represented about 5\% of all businesses with employees, with a combined turnover of about $£ 27$ billion, or $1.3 \%$ of the total turnover for all businesses with employees. Their contribution to GDP was estimated to be $£ 8.4$ billion."

In summary, the Social Enterprise Action Plan estimates that there are 55,000 social enterprises with $£ 27$ billion turnover per year contributing more than $£ 8$ billion to GDP per year.

Personally, I feel that this may be an over estimation as firstly, they have adopted a very broad definition for a "social enterprise" (see Section 2); secondly, the statistics are estimates from a wider study on small businesses; and thirdly, the Social Enterprise Action Plan was putting forward the argument for support to the social enterprise sector.

In 2005 the DTI made an estimate of Scottish social enterprises and reckoned that there are...

“...at least 1,100 social enterprises in Scotland, employing 30,000 people and adding £1.25 billion to the national economy" (see www.senscot.net)

More recently evidence suggests there could be more than 3,000 social enterprises in Scotland. This figure has come from the Scottish Government supported Better Business: A strategy and Action Plan for Social Enterprise in Scotland (2007) and states that the 2005 study...

“....did not take account of all types of company form used by social enterprise...”

On balance, I feel we can safely estimate that there are around 3,000 social enterprises operating in Scotland.

\section{SUPPORT TO SOCIAL ENTERPRISE}

\subsection{Governmental support}

Social enterprise currently enjoys a very positive image in the UK and it is mentioned by all government departments and is on the agenda of all political parties. The department that now has responsibility for social enterprise support is the Department for Communities and Local Government (DCLG). Some observers feel that social enterprise has been "down graded", as responsibility for social enterprise used to lie with the more influential Department for Trade and Industry. However, the Minister appointed for Enterprise covers social enterprise to some degree.

The UK Government sees social enterprise as having a significant role in combating social exclusion; fulfilling public services on contract; helping in the regeneration of disadvantaged areas; stimulating local economies; and working with socially excluded groups.

In practical terms, the government has provided written guidance and advice on tendering for public 
sector contracts for local government and social enterprises; and papers on how local communities can buy local land and property (thus creating an asset which can be used as collateral if the social enterprise wishes to borrow to expand).

In terms of funding, the government has also set aside funds for a "Change Up" funding programme which enabled voluntary organisations to operate more like social enterprises ie. changing $u p$ to be more business-like and enterprising. The government has also made it a requirement that all Regional Development Agencies (RDAs) should have their own written plans to work effectively with social enterprises in their regions. Another possible measure, which has not been decided upon yet, is that government is considering using the money from un-used bank accounts to be collected in a fund - a proportion of which that can benefit social enterprises.

In terms of advice, guidance and training for social enterprises, the government expects Business Links in each of the regions in the UK (called the Small Business Gateway in Scotland) to offer specialist support to those wanting to set up social enterprises. In Scotland, Scottish Enterprise and the local enterprise companies should support social enterprise with advice and practical help; and Communities Scotland has written the Strategy for Social Enterprise which is an action plan to expand the sector. In addition, each local authority has an economic development department which can provide advice as well as grants for voluntary organisations and social enterprises.

\subsection{Non-governmental support}

The government often funds autonomous social economy support organisations and in Scotland there are a plethora of organisations offering support and networking facilities to social enterprises. Some of them are:

Scottish Social Enterprise Coalition providing co-ordination of social enterprise support organisations; promoting the sector; generating publicity for the sector

Development Trust Association Scotland supporting, networking and sharing ideas amongst development trusts

Social Enterprise Academy providing training and learning for social enterprises and social entrepreneurs

Senscot providing a networking service for social enterprises and social entrepreneurs

Community Recycling Network Scotland which works with recycling and environmental bodies

....and there are many more some only covering regions and not the whole of the country.

\section{OTHER FACTORS INFLUENCING SOCIAL INCLUSION STRATEGIES}

\subsection{Local compacts and social inclusion (www.thecompact.org.uk)}

Local compacts are partnership agreements between local government, local public bodies and the voluntary and community sectors in the provision of local services. $99 \%$ of local authority areas in England are now covered by a local compact but it does not operate in Scotland although there are close equivalents in Scotland (eg. Community Planning).

"Compact" was launched in 1998 and before that over 25,000 organisations were consulted to explore ideas on how the Compact idea could work. The first Local Compact was published in 1999 by Dorset County and the idea of the Compact has since attracted attention from over 25 nations worldwide. 
The Compact was developed from recommendations made by the Deakin Commission Report on the Future of the Voluntary Sector and from the policy document Building the Future Together. The Deakin Commission concluded that the government should recognise the legitimacy of the voluntary and community sector's diverse roles and its own responsibility to promote a healthy voluntary sector. It proposed a 'concordat' drawn up between representatives of government and the sector, laying down basic principles for future relations. Building the Future Together concluded that a Compact, underpinned by a set of principles, was necessary as the basis for a partnership between government and the voluntary and community sector.

The independent body Compact Voice (www.compactvoice.org.uk) represents the views of the voluntary and community sector on the Compact. Compact Voice has representative members from national voluntary organisations and umbrella bodies with a national, regional and local reach. Compact Voice meets quarterly with the Commission for the Compact, Government Ministers and the Local Government Association, at an Annual Meeting to review progress on the Compact and agree an action plan for the following year. In addition, Compact Voice's open events are often preceded by meetings of this network and there is usually at least one training event a year for members. Compact Voice currently keeps a progress list on local Compacts across all 388 local authority areas in England this is used as evidence of the extent of Local Compacts.

It's associate body Local Compact Voice acts as a network for over 300 members from across England who work on Local Compacts as all or part of their jobs. Local Compact Voice functions primarily as an e-mail group to exchange information and receive regular briefings.

Both Compact Voice and Local Compact Voice work together with Government and the Commission for the Compact to improve the relationship between the voluntary sector, government and local public bodies for mutual advantage and community gain. The Compact network enables members to draw on expert Compact experience and problem solving from around England and to influence national policy on local Compact related issues. There is also a Local Compact Implementation Workbook produced by Compact Voice which is a useful practical tool for local areas to get the most out of local Compacts.

Local Compacts are crucial to local relationships and are instrumental to improving these local relationships. The key to Local Compacts are links to local policy including Local Area Agreements and Local Strategic Partnerships.

Local Compacts play a part in tackling social exclusion at a local level as they enable a range of organisations to work together in concerted way.

\subsection{Local Strategic Partnerships and social inclusion (www.communities.gov.uk)}

The Government's Department of Communities and Local Government (DCLG) believes more gets done if people and organisations in an area work together. These area-based organisations might include community and faith groups, the council, police and fire and rescue services, charity groups, businesses, schools, health bodies and more. The government believes that pooling experience and expertise can help to understand local people, places and problems and make sure the right actions are taken and right services delivered. This linking is known as a Local Strategic Partnership (LSP) and is really an extension of local Compacts but operating in mainly disadvantaged areas.

LSPs are non-statutory, multi-agency partnerships, which match local authority boundaries. They bring together, at a local level, the different parts of the public, private, community and voluntary sectors. They allow different initiatives and services to support one another so that they can work together more effectively. The LSPs hold meetings to share information and provide the basis of working together. 
In detail, LSPs do a number of different things including:

- bringing together at a local level the different parts of the public sector as well as the private, business, community and voluntary sectors so that different initiatives and services support each other and work together;

- $\quad$ providing a single overarching local co-ordination framework within which other partnerships can operate;

- developing and driving the implementation of Community Strategies and Local Area Agreements (LAAs);

- $\quad$ being responsible for agreeing the allocation of this funding and helping to 'narrow the gap' in areas receiving Neighbourhood Renewal Funding (NRF).

Sometimes LSPs are known by other names like 'Anytown Ahead' or 'Anyplace Partnership'. It is reported that many are starting to make a real difference particularly in very deprived districts - the Neighbourhood Renewal areas.

The membership and the specific functions of the LSPs vary from place to place depending on the local issues that need tackling. LSPs will become more and more important as they drive Local Area Agreements (LAAs). LAAs set out the priorities for a local area agreed between central government and a local area (the local authority and Local Strategic Partnership) and other key partners at the local level. LAAs can simplify some central funding, help join up public services more effectively and allow greater flexibility for local solutions to local circumstances. Through these means, LAAs are helping to devolve decision making, to move away from a 'Government-knows-best' philosophy and to reduce bureaucracy.

LSPs have been very instrumental in addressing issues around social exclusion.

\subsection{Social Accounting and Audit and social inclusion (www.socialauditnetwork.org.uk)}

Social accounting and audit is a framework which allows a social enterprise to fully account for its performance and impact on its main stakeholders and society generally. It measures performance and impact in terms of social (affect on society); environmental (affect on the environment); economic (affect on the economy). It is a self monitoring and evaluating system with an external audit to verify the claims made by the social enterprise.

The social accounting and audit framework involves three steps for an enterprise. The first step is about organisations clarifying their mission, objectives and related activities, and the values and principles that under-pin all their actions, as well as identifying their key stakeholders. The second step involves recognising the quantitative and qualitative indicators that enable the enterprise to report effectively on its performance and impact against its stated mission, objectives and values through data collection and consulting appropriately with its key stakeholders. The third step is about bringing all the collected information together into social accounts that are then verified by an independent panel that, once satisfied, issues a social audit statement. Most enterprises keep social accounts for a period which usually runs concurrent with their financial year. From experience SAN has discovered that the first step should be preceded by a preparatory "getting ready" stage especially for enterprises embarking on social accounting for the first time.

Social enterprises which practise social accounting and audit report that it provides a framework for their business management, on-going monitoring and an annual evaluation of their performance and impact - socially, economically and environmentally. It is a framework which can be used to prove to all stakeholders what has, and has not, been achieved; and to identify how the enterprise can improve. Social accounting lends itself effectively to "triple bottom line" accounting as it expects the social 
accounts to refer to social, economic and environmental aspects - positioning them beside financial accounts thus giving a 360 degree account of the enterprise's activities and impacts.

There is significant evidence to suggest that social accounting and audit has enabled trading social enterprises and co-operatives to obtain contracts and investment as, using social accounting and audit, they can demonstrate their wide benefits to society.

In the UK, Social Accounting and Audit is actively promoted by the Social Audit Network (SAN)(see www.socialauditnetwork.org.uk) SAN supports social accounting as the preferred means whereby social enterprises report on their social, environmental and economic performance and impact. SAN is a network of social accounting practitioners and it regularly distributes and exchanges relevant information through a growing email network worldwide (currently 1,500 email subscribers); provides training and support in social accounting and audit; and manages a register of SAN Approved Social Auditors.

SAN has worked with a range of social enterprises and voluntary organisations throughout the UK supporting them to prepare social accounts and have them independently audited. SAN tends to work using a "cluster model" and in recent years has worked with clusters in Fife, Edinburgh, Glasgow, Moray and Aberdeenshire, West Midlands, East Midlands, Merseyside, Wales, North East England and South West England.

In summary, Social Accounting and Audit is used by social enterprises to account for their social, environmental and economic performance and impact. This checking can ensure that a social enterprise is making an impact on social exclusion in communities.

\subsection{Community Interest Companies and social inclusion (www.cicregulator.gov.uk)}

Community Interest Companies (CICs) are companies, with special additional features, created for the use of people who want to conduct a business or other activity for community benefit and not purely for private advantage. They are a new type of limited company designed specifically for those wishing to operate for the benefit of the community rather than for the benefit of the owners of the company.

This means that a CIC cannot be formed or used solely for the personal gain of a particular person, or group of people. This is achieved by a applying a "community interest test" and "asset lock" which ensures that the CIC is established for community purposes and the assets and profits are dedicated to these purposes.

CICs can be limited by shares, or by guarantee, and have a statutory "asset lock" to prevent the assets and profits being distributed, except as permitted by legislation. This ensures the assets and profits are retained within the CIC for community purposes or transferred to another asset-locked organisation, such as another CIC or charity. A CIC cannot be formed to support political activities and a company that is a charity cannot be a CIC, unless it gives up its charitable status. However, a charity may apply to register a CIC as a subsidiary company.

Registration of a company as a CIC has to be approved by the Regulator who also has a continuing monitoring and enforcement role. The Companies (Audit, Investigations and Community Enterprise) Act 2004 established the Regulator as an independent public office holder appointed by the Secretary of State for Trade and Industry. The Government expects the Regulator to be a "light touch regulator" who will encourage the development of the CIC brand and provide guidance and assistance on matters relating to CICs.

The idea of CICs came about with the increase in the social enterprise sector. Some of the legal forms available were originally designed for completely different types of organisation. The Government 
wanted to support the sector by creating a modern and appropriate legal vehicle for social enterprises and to help raise their profile. Currently companies that do not have charitable status find it difficult to ensure that their assets are dedicated to public benefit and there was no simple, clear way of locking assets to a public benefit purpose other than applying for charitable status. The Community Interest Company helps to meet the need for a transparent, flexible model, clearly defined and easily recognised.

A charitable company registered in England or Wales can convert to a CIC with the consent of the Charity Commissioners. In so doing it will lose its charitable status including tax advantages. A charity may, however, own a CIC in which case the CIC would be permitted to pass assets to the charity. CICs will be free to operate more "commercially" than charities (e.g. CICs limited by shares can pay dividends to individual shareholders, subject to a cap), but stakeholders in CICs will still have the assurance of community benefit provided by the "asset lock" and transparency about their activities ability through the community interest report which is very similar to the social report in social accounting and audit.

Social enterprises often attempt to tackle social exclusion. CICs can provide a legal structure for social enterprises. However, they do not offer the same tax advantages that charities can obtain. The traditional structure for social and community enterprises was to have a charitable holding company limited by guarantee with a wholly-owned trading subsidiary - which trades and annually covenants any surplus back to the holding company thus avoiding tax. CICs are unable to avoid paying tax in this way and thus have not been very popular in Scotland. In England, however, they are more popular as traditionally it has been much harder to form a charity in England. The vast majority of social enterprises adopting the CIC structure are those that are newly formed. There are not so many organisations converting to CICs - but it is still early days.

\section{SOME ISSUES FACING THE SOCIAL ENTERPRISE SECTOR}

- There is disagreement over the definition of social enterprise and because of that some people form their own interpretations of what is and what is not a social enterprise.

- The support required by social enterprises is fairly specialised. A social enterprise often tries to seek support from people and organisations that have experience of social enterprise development and there are not many people who have the appropriate skills and experience. Organisations are now trying a "mentoring" approach.

- $\quad$ Certainly in Scotland there are too many different support organisations providing overlapping services to social enterprises.

- $\quad$ Social enterprises are not used to winning large scale public sector contracts and they have a casual approach to business contracts.

- There is no agreed method to measure and explain performance and impact - need for more widespread use of Social Accounting and Audit.

- There is no clear and distinct legal structure for social enterprise. Social enterprises have had to adopt and adapt a structure from Company Law whose structure is cumbersome and difficult to manage. The current UK government is aware of this and in 2005 introduced legislation specific for social enterprises (Community Interest Companies). For a number of reasons social enterprises have been slow to adopt the CIC structure. 


\section{REFERENCES}

Community Interest Company website: www.cicregulator.gov.uk.

Compact websites: www.thecompact.org.uk and www.compactvoice.org.uk.

CONSCISE Programme website: $\underline{w w w . c o n s c i s e . i n f o}$.

Deakin Commission Report, Future of the Voluntary Sector.

Department of Trade and Industry, Small Business Service, Annual Small Business Survey, London, 2005.

IFF Research, A Survey of Social Enterprise Across the UK, London, Small Business Service, 2005 Government website on local strategic partnerships: www.communities.gov.uk.

Pearce, J., Social Enterprise in Anytown; Calouste Gulbenkian Foundation, 2003.

Scottish Government, Better Business: A strategy and Action Plan for Social Enterprise in Scotland, 2007.

Scottish Social Enterprise Coalition website: www.ssec.org.uk.

Senscot website: $\underline{w w w . s e n s c o t . n e t}$.

Social Audit Network website: www.socialauditnetwork.org.uk.

Social Enterprise Unit, Department of Trade and Industry (DTI), Social Enterprise Action Plan: Scaling New Heights, 2006. 